\title{
Cytolethal distending toxins in Shiga toxin- producing Escherichia coli: alleles, serotype distribution and biological effects
}

\author{
Dorothea Orth, Katharina Grif, Manfred P. Dierich and Reinhard Würzner
}

Correspondence

Dorothea Orth

dorothea.orth@i-med.ac.at

Received 6 April 2006

Accepted 9 August 2006
Department of Hygiene, Microbiology and Social Medicine, Innsbruck Medical University and Austrian Reference Laboratory for Enterohaemorrhagic Escherichia coli, Schöpfstr. 41, A-6020 Innsbruck, Austria

To assess the prevalence of cytolethal distending toxin (CDT) among Shiga toxin-producing Escherichia coli (STEC), 202 STEC strains were investigated using PCRs targeting various cdt alleles ( $c d t-/$ to $c d t-V$ ). Seven of the 202 strains contained $c d t-I / I$ and an additional seven contained $c d t-V$. All 14 cdt-positive strains produced biologically active CDT, as demonstrated by a progressive distension of cultured Chinese hamster ovary cells. The CDT-positive STEC belonged to eight different serotypes, including sorbitol-fermenting O157 : NM (non-motile). The data demonstrate that CDT is present in some STEC serotypes only. However, more studies are required to evaluate whether CDT presence is associated with severe disease.

\section{INTRODUCTION}

The cytolethal distending toxin (CDT) was first described in 1987 as a novel toxin occurring in diarrhoeagenic Escherichia coli (Johnson \& Lior, 1987). During the years following, closely related toxins were also detected in other intestinal and extraintestinal pathogens, such as Campylobacter spp. (Johnson \& Lior, 1988a; Pickett et al., 1996), Shigella spp. (Okuda et al., 1995), Salmonella typhi (Haghjoo \& Galan, 2004), Haemophilus ducreyi (Cope et al., 1997), Actinobacillus actinomycetemcomitans (Mayer et al., 1999) and Helicobacter spp. (Chien et al., 2000; Young et al., 2000). The members of the CDT family are usually encoded by a cluster of three genes $(c d t A, c d t B, c d t C)$ which encode the three proteins of the CDT holotoxin (Cortes-Bratti et al., 2001a; Lara-Tejero \& Galan, 2001). CDTs cause G1 or G2 cell cycle arrest in mammalian cells (Cortes-Bratti et al., 2001b), leading to the inhibition of proliferation, the characteristic distended cell morphology, and ultimately cell death (Bielaszewska et al., 2005a; Lara-Tejero \& Galan, 2001). Because they interfere with the cell cycle, CDTs are classified as cyclomodulins (Nougayrede et al., 2005).

A total of five different $c d t$ alleles ( $c d t-I, c d t-I I, c d t-I I I, c d t-I V$ and $c d t-V$ ) have been reported in E. coli (Janka et al., 2003; Peres et al., 1997; Pickett et al., 1994; Scott \& Kaper, 1994; Toth et al., 2003), but there is only limited knowledge available on the epidemiology of the strains harbouring these genes and/or producing CDT. The strains have been

\footnotetext{
Abbreviations: $\mathrm{CDT}$, cytolethal distending toxin; $\mathrm{CHO}$, Chinese hamster ovary; HUS, haemolytic uraemic syndrome; NM, non-motile; NSF, nonsorbitol fermenting; SF, sorbitol fermenting; STEC, Shiga toxinproducing Escherichia coli.
}

isolated from patients with diarrhoea (Albert et al., 1996; Ansaruzzaman et al., 2000; Johnson \& Lior 1988b; Okeke et al., 2000) and non-intestinal diseases (Dobrindt et al., 2003; Johnson \& Stell, 2000; Johnson et al., 2002). In several studies, the prevalence of $c d t$ among $E$. coli isolated from non-intestinal infections, including urosepsis (8\%) (Johnson \& Stell, 2000) and meningitis (46\%) (Johnson et al., 2002), was higher than that in isolates from patients with diarrhoea $(1 \cdot 6-6 \cdot 4 \%)$ (Albert et al., 1996; Okeke et al., 2000). In addition to human E. coli isolates, CDT production and/or $c d t$ genes have also been identified, with varying frequencies, in E. coli isolated from both diseased and healthy animals, including cattle (Clark et al., 2002; Mainil et al., 2003), pigs (daSilva \& daSilva Leite, 2002; Mainil et al., 2003; Toth et al., 2003) and dogs (Mainil et al., 2003; Starcic et al., 2002), as well as various species of wild birds (La Ragione \& Woodward, 2002; Morabito et al., 2001; Sonntag et al., 2005a). The fact that different $c d t$ alleles were targeted in the various human and animal isolates makes it difficult to draw any conclusions on the epidemiological relationships among $\mathrm{CDT}^{+}$E. coli strains from the various sources.

Although some E. coli isolates identified as $c d t^{+} / \mathrm{CDT}^{+}$also possess stx genes (Clark et al., 2002; Johnson \& Lior 1988b; Morabito et al., 2001; Sonntag et al., 2005a), such strains originate mostly from animals, i.e. cattle (Clark et al., 2002) and pigeons (Morabito et al., 2001; Sonntag et al., 2005a). The presence of $c d t$ genes in Shiga toxin (Stx)-producing $E$. coli (STEC) from humans has rarely been observed (Bielaszewska et al., 2004; Clark et al., 2002; Johnson \& Lior, 1988b). However, $c d t-V$ has been detected in the majority $(87 \%)$ of sorbitol-fermenting (SF) STEC 
O157: NM (non-motile) strains in Germany (Janka et al., 2003) and in four similar isolates in Austria (Orth et al., 2006). In the present study, we assessed the prevalence of $c d t$ in STEC isolates belonging to a broad spectrum of serotypes and originating from various sources.

\section{METHODS}

Bacterial strains. Two hundred and two STEC strains from humans $(n=150)$, animals $(n=38)$ and food $(n=14)$ were investigated in this study. One hundred and thirty-two strains were positive for the intimin-encoding eae gene, which is located at the locus of enterocyte effacement (LEE); 70 strains were eae negative. The isolates were recovered at the Austrian Reference Laboratory for Enterohaemorrhagic Escherichia coli during routine diagnostic and epidemiological investigations between 2003 and 2005. The isolation of STEC strains from stools was performed as described previously (Friedrich et al., 2002). The 150 STEC strains originating from human stools were recovered from 12 patients with haemolytic uraemic syndrome (HUS), 101 patients with diarrhoea, 22 asymptomatic individuals and 15 individuals with unknown clinical diagnosis. The animal isolates all originated from cattle, except for one isolate that was found in a goat. The food isolates were recovered from raw meat $(n=13)$ and raw milk $(n=1)$. The 202 isolates belonged to 61 different serotypes (Table 1). Sixty strains contained $s t x_{1}$ only, 67 strains stx $x_{1}$ and $s t x_{2}$, and 75 strains stx $x_{2}$ only, as detected by PCR using primers KS7 and KS8, and LP43 and LP44 (Table 2).

PCRs. The PCR primers, target sequences and PCR conditions are listed in Table 2. E. coli strains 6468/62 (O86:H34; cdt-I $I^{+}$) (Scott \& Kaper, 1994), 9142/88 (O128: $\left.\mathrm{H}^{-} ; c d t-I I^{+}\right)$(Pickett et al., 1994), $1404\left(\mathrm{O} 78 ; c d t-I I I^{+}\right)$(Peres et al., 1997), 28c (O78; $\left.c d t-I V^{+}\right)$(Toth et al., 2003), and 493/89 (O157:NM; cdt- $V^{+}$) (Janka et al., 2003) were used as positive controls. They were kindly provided by $\mathrm{H}$. Karch (University of Münster), who had received the strains from D. A. Scott (University of Maryland School of Medicine), C. L. Pickett (University of Kentucky Medical Center) and E. Oswald (École nationale vétérinaire de Toulouse), or were isolated in his laboratory (strain 493/89).

CDT bioassay. CDT was assayed using Chinese hamster ovary $(\mathrm{CHO})$ cells and a modification of the procedure described by Scott
\& Kaper (1994). Briefly, supernatants of bacterial cultures grown overnight $\left(37^{\circ} \mathrm{C}, 180\right.$ r.p.m.) in cell culture medium (Ham's F12 with $10 \%$ fetal calf serum) were filter-sterilized $(0 \cdot 22 \mu \mathrm{m}$ pore-size filters; Corning), and $1 \mathrm{ml}$ portions of twofold dilutions of the filtrates were added in duplicate to $1 \times 10^{3} \mathrm{CHO}$ cells freshly seeded in $1.5 \mathrm{ml}$ Ham's F12 medium in six-well tissue culture plates (Falcon 3502; Becton Dickinson). The assay mixes were incubated for 4 days at $37^{\circ} \mathrm{C}$ in $5 \% \mathrm{CO}_{2}$ and examined daily for typical cell distension (Scott \& Kaper, 1994). The CDT titre was defined as the highest filtrate dilution that caused distension, evaluated as described elsewhere, in $50 \%$ of CHO cells (Bielaszewska et al., 2004, 2005a). SF STEC O157:NM strain 493/89 (CDT-V) served as a positive control, and $\mathrm{CHO}$ cells not exposed to culture filtrates as a negative control.

\section{RESULTS AND DISCUSSION}

\section{Frequency of cdt genes among STEC 0157}

We used a spectrum of PCR procedures to target various $c d t$ alleles, previously identified in E. coli strains ( $c d t-I, c d t-I I$, $c d t-I I I, c d t-I V$ and $c d t-V$ ), in STEC belonging to 61 different serotypes. In the E. coli $\mathrm{O} 157$ group, none of the 72 nonsorbitol-fermenting (NSF) E. coli O157:H7/NM strains possessed $c d t$. Friedrich and colleagues have recently shown that $c d t$ - $V$-positive O157:H7 strains belong to particular phage types (PTs), although the presence of $c d t$ within these PTs is not obligatory (Friedrich et al., 2006). Thus, they conclude that the proportion of $c d t$-V-positive STEC O157: H7 may depend on the PTs tested.

In contrast, five of eight SF STEC O157: NM strains were positive for $c d t-V$ (Table 3). The association of $c d t-V$ with SF STEC O157 : NM confirms the data of Janka et al. (2003). However, in contrast to these authors, who found $c d t-V$ in six out of 100 NSF E. coli O157: H7 (Janka et al., 2003), we found neither $c d t-V$ nor any of the other $c d t$ alleles in any of the 72 NSF E. coli O157: H7/NM strains. In addition to $c d t$, SF E. coli $\mathrm{O} 157$ : NM also possess additional loci which are

Table 1. Distribution of serotypes of the 202 investigated STEC strains

ONT, O non-typeable.

\begin{tabular}{|lc|}
\hline Serotype & Number of strains \\
\hline O157:H7/NM & 72 \\
O26:H11/NM & 18 \\
O146:H28/H21/NM & 9 \\
SF O157:NM, O125:H8/H7/H4, O103:H21/H7/H2/NM & 8 \\
O145:NM & 7 \\
O177:NM, O111:H8/NM, O114:H18, O113:H4 & 4 \\
O175:H40/H8, O127:H40, O116:NM, O91:H21/NM, O76 :H21/H19 & 3 \\
O174:H21/H2, O163:H19/NM, O158:H40/H18, O128:H8/H2, & 2 \\
O100:NM, O75:H8, O8:H25, O6 :H10, O5:NM & \\
O185:H28, O182:H16, O143:H11, O139:H25, O119:H4, O118:H11, & 1 \\
O112:H18, O84:H2, O82:H11, O55:H7, O22:NM, O20:NM, & \\
O17:H45, Orough $: \mathrm{H} 21$ & \\
ONT:H28/H18/H12/H8/NM & 9 \\
\hline
\end{tabular}


Table 2. PCR primers and conditions used to detect eae, stx and cdt genes

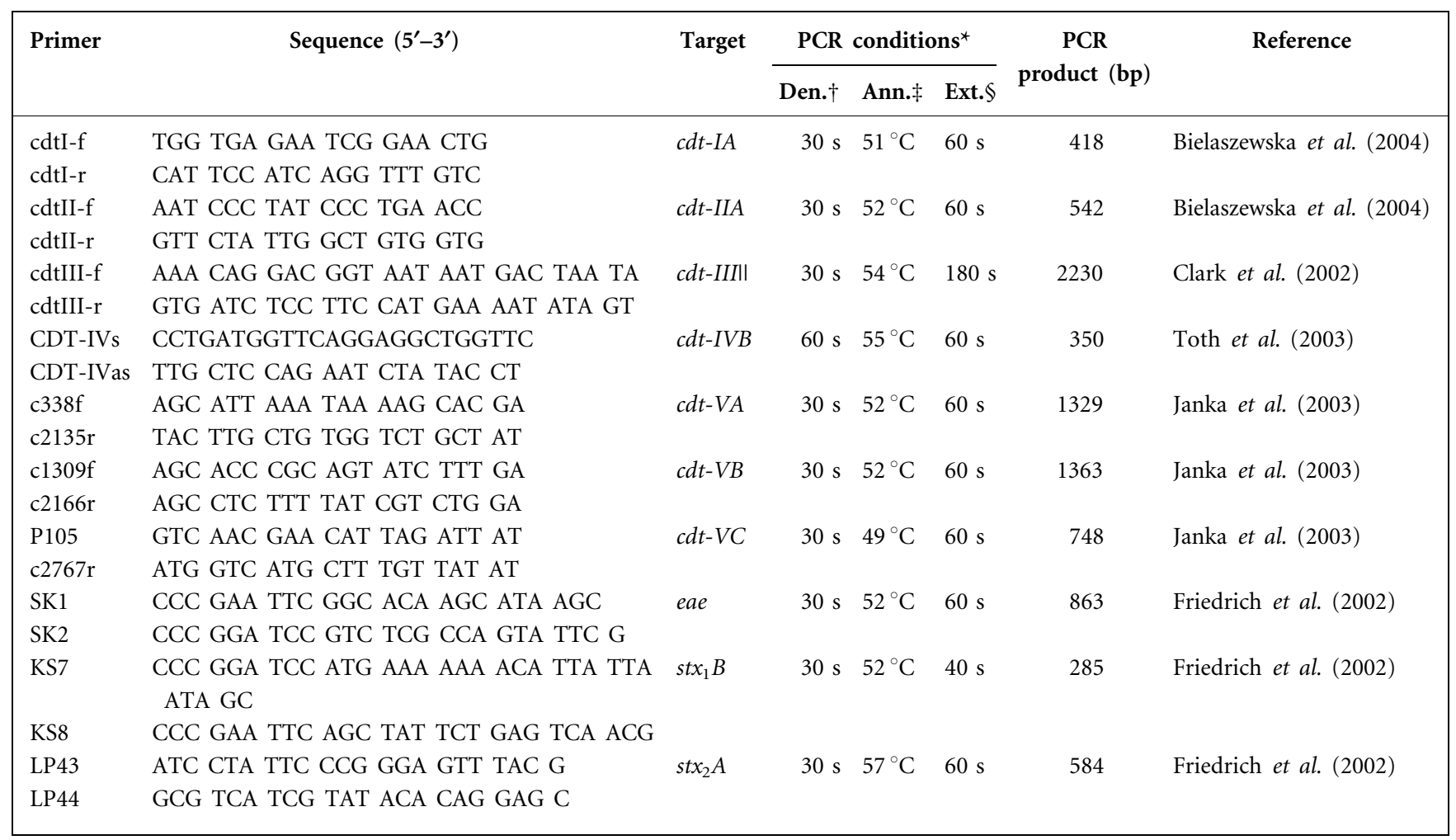

${ }^{*}$ All PCRs were performed in 30 cycles with final extension of $5 \mathrm{~min}$ at $72{ }^{\circ} \mathrm{C}$.

$\dagger$ Den., denaturing (all reactions at $94{ }^{\circ} \mathrm{C}$ ).

$\ddagger$ Ann., annealing (all reactions $60 \mathrm{~s}$ ).

§Ext., extension (all reactions at $72^{\circ} \mathrm{C}$ ).

IIComplete.

absent from NSF E. coli O157: H7/NM. These include efa1, $s f p A$ and a mosaic island composed of the loci of the genome of E. coli O157 : H7 strain EDL933 and the Shigella resistance locus (Friedrich et al., 2004; Janka et al., 2002, 2005). However, SF STEC O157: NM lack the gene clusters which encode urease and tellurite resistance in E. coli O157:H7

Table 3. Distribution of $c d t-I, c d t-I I, c d t-I I I, c d t-I V$ and $c d t-V$ alleles among STEC strains, and CDT production

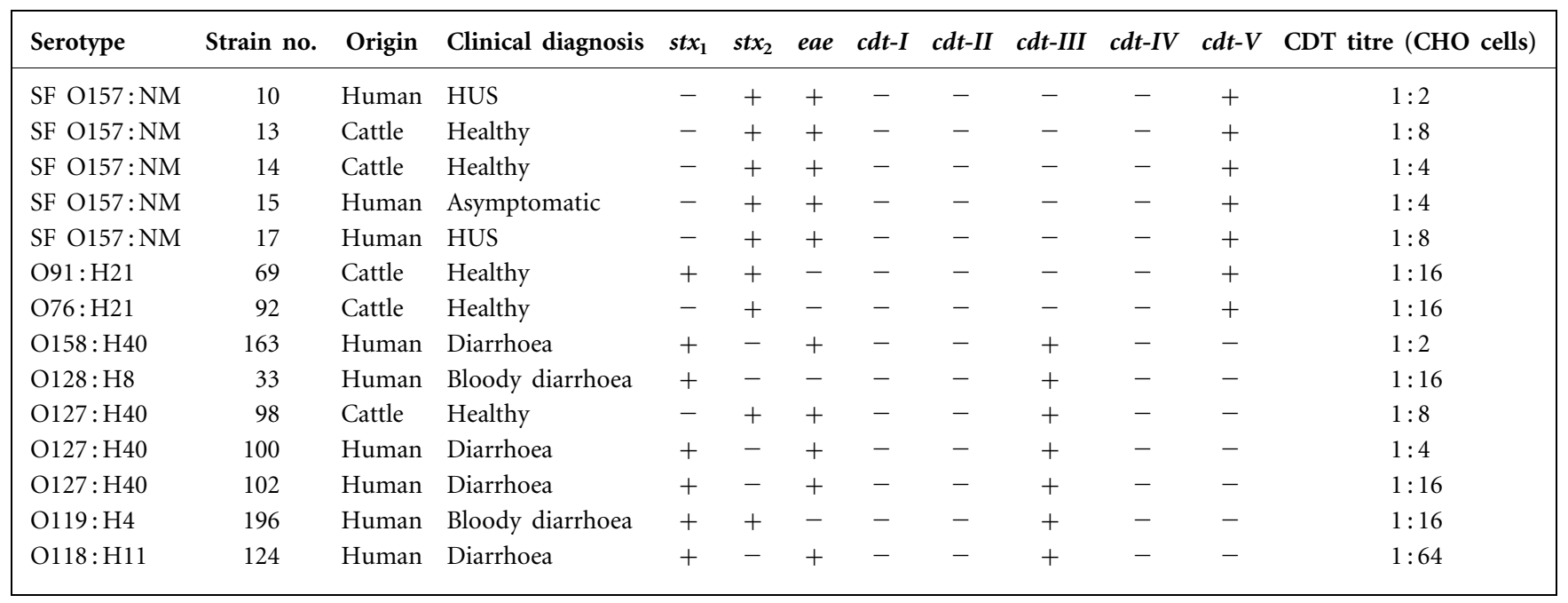


(Bielaszewska et al., 2005b; Friedrich et al., 2005), which implies that different spectra of virulence factors are present.

\section{Frequency of cdt genes among STEC non-0157}

Of the 122 STEC isolates belonging to 58 different non-O157 serotypes, nine $(7 \cdot 4 \%)$ tested positive for $c d t$ genes. Serotypes of the $c d t$-positive strains are shown in Table 3. In contrast to SF STEC O157: NM, which contained only $c d t-V$, seven of nine non-O157 STEC contained $c d t-I I I$, and two of these harboured $c d t-V$ (Table 3 ). We demonstrated the presence of $c d t$-III in three STEC strains belonging to serotype $\mathrm{O} 127$ : H40. Interestingly, E. coli isolates of serotype O127:NM have been the most prevalent $\mathrm{CDT}^{+}$strains found among enteropathogenic E. coli (EPEC) in several studies (Albert et al., 1996; Ansaruzzaman et al., 2000). The presence of only $c d t-I I I$ and $c d t-V$ in this study is in agreement with earlier studies from Germany (Bielaszewska et al., 2004) and North America (Pickett et al., 2004), in which only these two alleles have been identified. However, $c d t$ - $I$ was the only $c d t$ allele found in STEC strains isolated in Iran (Bouzari et al., 2005). Altogether, these data suggest that differences may exist in $c d t$ alleles occurring in STEC strains from different geographical regions. Neither in our study nor in earlier studies from other countries (Bielaszewska et al., 2004, 2005c; Pickett et al., 2004; Prager et al., 2005) were $c d t$ genes identified in STEC of the major non-O157 serogroups associated with human disease, such as O26, O103, O111 and O145, which, however, are mostly eae positive (Bielaszewska et al., 2005c; Friedrich et al., 2002).

\section{Distribution of cdt-positive STEC among human and environmental isolates}

$c d t$ genes, including $c d t-I I I$ and $c d t-V$, were found in nine $(6 \cdot 0 \%)$ of 150 human isolates, in five $(13 \cdot 2 \%)$ of 38 animal isolates, and in none of 14 food isolates. The origins of the STEC isolates harbouring $c d t-I I I$ and $c d t-V$ are shown in Table 3. Eight of the nine human $c d t$-positive isolates originated from diseased persons, including two patients with HUS and two patients with bloody diarrhoea (Table 3 ). The presence of $c d t$ - $V$ in STEC strains isolated from patients with severe disease, including HUS, supports reports by other investigators (Bielaszewska et al., 2004; Janka et al., 2003; Prager et al., 2005). Our finding of $c d t$ in STEC isolated from cattle is in agreement with the report of Clark et al. (2002). Moreover, the absence of $c d t$ from the goat STEC isolate investigated in our study is in accordance with previous studies by other authors (Morabito et al., 2001; Sonntag et al., 2005a) which suggest species-specific differences in the prevalence of $c d t$ among STEC of animal origin. Specifically, whereas $c d t$ genes are regularly found in STEC strains isolated from pigeons (Morabito et al., 2001; Sonntag et al., 2005a), STEC isolated from pigs with oedema disease or diarrhoea lack $c d t$ (Sonntag et al., $2005 \mathrm{~b})$. Since $c d t$ in STEC occurs in a variety of serotypes from a number of different origins, it is possible that these genes spread horizontally. Janka and colleagues have shown that the $c d t-V$ gene in SF STEC O157:NM is flanked by sequences of bacteriophage P2 (Janka et al., 2003), suggesting that the gene might have been acquired by phage transduction (Janka et al., 2003). In contrast, the $c d t$-III gene cluster in STEC has been shown to be plasmidborne (Bielaszewska et al., 2004). Thus, conjugation could represent a mechanism by which $c d t-I I I$ is spread among STEC strains.

\section{Association of cdt genes with the eae gene}

Ten $(7 \cdot 6 \%)$ of 132 eae-positive and four $(5 \cdot 7 \%)$ of 70 eaenegative STEC possessed $c d t-I I I$ or $c d t-V$, demonstrating that there was no significant difference in the prevalence of
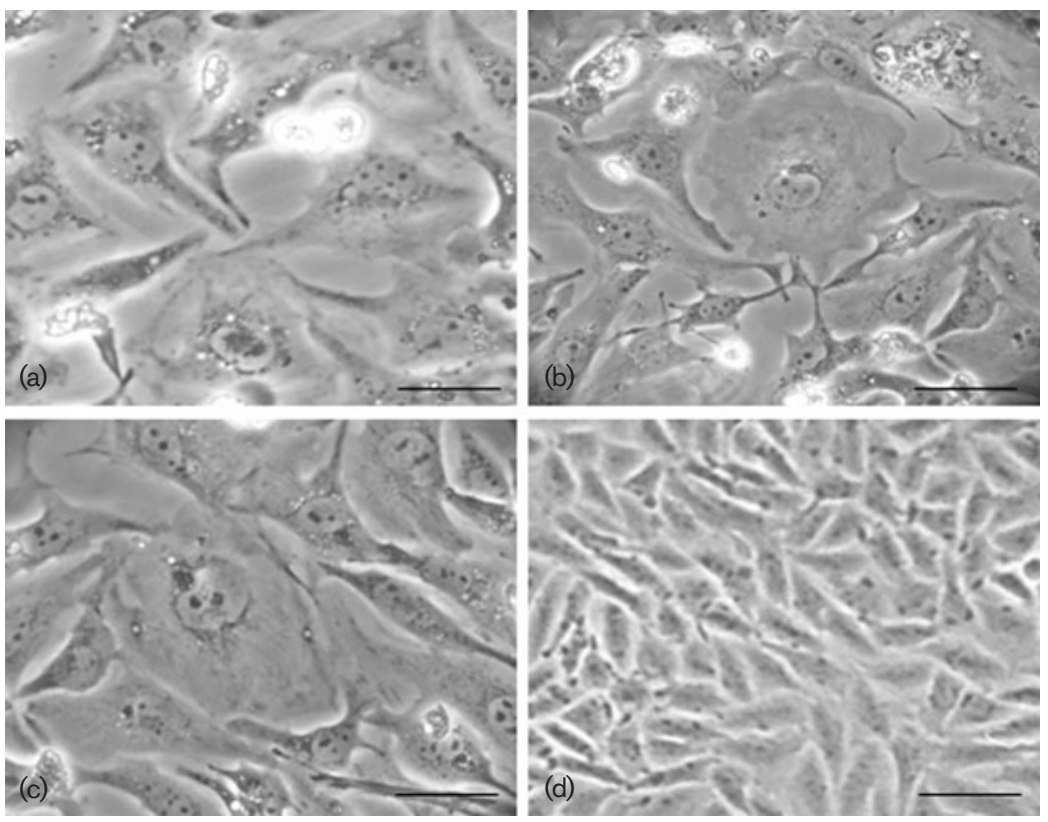

Fig. 1. Photomicrographs of $\mathrm{CHO}$ cells after 4 days' incubation with culture filtrates from CDT-V ${ }^{+}$control strain 493/89 (a), STEC strain 69 (O91: $\mathrm{H} 21)$ producing CDT-V (b), and STEC strain 33 (O128: H8) producing CDT-III (c). (d) $\mathrm{CHO}$ cells incubated for 4 days in Ham's F12 medium only, in the absence of any CDTs. Bars, $75 \mu \mathrm{m}$. 
$c d t$ between eae-positive and eae-negative STEC from our collection. Moreover, eae was found in the same frequency among $c d t$-III-positive and $c d t$-V-positive STEC strains (Table 3). These data demonstrate that there is no association between a particular $c d t$ allele and the presence of eae in STEC. Our finding of $c d t$ in non-O157 STEC carrying eae extends the findings of previous studies in which $c d t$ in non-O157 STEC was restricted to eae-negative STEC strains (Bielaszewska et al., 2004; Prager et al., 2005).

\section{CDT-III and CDT-V expression in STEC}

Of the 14 STEC strains harbouring $c d t-I I I$ or $c d t$ - $V$ genes, all produced active $\mathrm{CDT}$ according to the $\mathrm{CHO}$ cell assay. This was evidenced by a progressive distension in $\mathrm{CHO}$ cells for up to 4 days after exposure to culture filtrates of the STEC strains. The CDT titres ranged from 1:2 to $1: 64$ (Table 3 ). There was no difference in CDT titre between strains harbouring $c d t$-III and those harbouring $c d t-V$ (Table 3). The typical distending effects of STEC isolates producing CDT-III or CDT-V are demonstrated in Fig. 1.

In conclusion, we demonstrate that two different $c d t$ alleles encode biologically active CDT in STEC of particular serotypes, some of which are associated with severe human diseases, including HUS and bloody diarrhoea. Further investigation is necessary to clarify the mechanisms that govern the $c d t$ genetic coding and spread among STEC strains, and to determine the role of CDT in the pathogenesis of STEC-mediated diseases.

\section{ACKNOWLEDGEMENTS}

We thank Professor H. Karch (University of Münster) for providing us with $c d t$-positive control strains and for stimulating discussions. We thank C. Ortner, A. Rief and G. Hechenblaikner for excellent technical assistance. This study was supported by the Network of Excellence EuroPathoGenomics (LSHB-CT-2005-512061).

\section{REFERENCES}

Albert, M. J., Faruque, S. M., Faruque, A. S., Bettelheim, K. A., Neogi, P. K., Bhuiyan, N. A. \& Kaper, J. B. (1996). Controlled study of cytolethal distending toxin-producing Escherichia coli infections in Bangladeshi children. J Clin Microbiol 34, 717-719.

Ansaruzzaman, M., Albert, M. J., Nahar, S., Byun, R., Katouli, M., Kuhn, I. \& Mollby, R. (2000). Clonal groups of enteropathogenic Escherichia coli isolated in case-control studies of diarrhoea in Bangladesh. J Med Microbiol 49, 177-185.

Bielaszewska, M., Fell, M., Greune, L., Prager, R., Fruth, A., Tschäpe, H., Schmidt, M. A. \& Karch, H. (2004). Characterization of cytolethal distending toxin genes and expression in Shiga toxinproducing Escherichia coli strains of non-O157 serogroups. Infect Immun 72, 1812-1816.

Bielaszewska, M., Sinha, B., Kuczius, T. \& Karch, H. (2005a). Cytolethal distending toxin from Shiga toxin-producing Escherichia coli O157 causes irreversible G2/M arrest, inhibition of proliferation, and death of human endothelial cells. Infect Immun 73, 552-562.
Bielaszewska, M., Tarr, P. I., Karch, H., Zhang, W. \& Mathys, W. (2005b). Phenotypic and molecular analysis of tellurite resistance among enterohemorrhagic Escherichia coli O157:H7 and sorbitolfermenting O157:NM clinical isolates. J Clin Microbiol 43, 452-454.

Bielaszewska, M., Zhang, W., Tarr, P. I., Sonntag, A. K. \& Karch, H. (2005c). Molecular profiling and phenotype analysis of Escherichia coli O26:H11 and O26:NM: secular and geographic consistency of enterohemorrhagic and enteropathogenic isolates. J Clin Microbiol 43, 4225-4228.

Bouzari, S., Oloomi, M. \& Oswald, E. (2005). Detection of the cytolethal distending toxin locus $c d t B$ among diarrhoeagenic Escherichia coli isolates from humans in Iran. Res Microbiol 156, 137-144.

Chien, C. C., Taylor, N. S., Ge, Z., Schauer, D. B., Young, V. B. \& Fox, J. G. (2000). Identification of $c d t B$ homologues and cytolethal distending toxin activity in enterohepatic Helicobacter spp. J Med Microbiol 49, 525-534.

Clark, C. G., Johnson, S. T., Easy, R. H., Campbell, J. L. \& Rodgers, F. G. (2002). PCR for detection of $c d t$-III and the relative frequencies of cytolethal distending toxin variant-producing Escherichia coli isolates from humans and cattle. J Clin Microbiol 40, 2671-2674.

Cope, L. D., Lumbley, S., Latimer, J. L. \& 8 other authors (1997). A diffusible cytotoxin of Haemophilus ducreyi. Proc Natl Acad Sci U S A 94, 4056-4061.

Cortes-Bratti, X., Frisan, T. \& Thelestam, M. (2001a). The cytolethal distending toxins induce DNA damage and cell cycle arrest. Toxicon 39, 1729-1736.

Cortes-Bratti, X., Karlsson, C., Lagergard, T., Thelestam, M. \& Frisan, T. (2001b). The Haemophilus ducreyi cytolethal distending toxin induces cell cycle arrest and apoptosis via the DNA damage checkpoint pathways. J Biol Chem 276, 5296-5302.

daSilva, A. S. \& daSilva Leite, D. (2002). Investigation of putative CDT gene in Escherichia coli isolates from pigs with diarrhea. Vet Microbiol 89, 195-199.

Dobrindt, U., Agerer, F., Michaelis, K. \& 7 other authors (2003). Analysis of genome plasticity in pathogenic and commensal Escherichia coli isolates by use of DNA arrays. J Bacteriol 185, 1831-1840.

Friedrich, A. W., Bielaszewska, M., Zhang, W.-L., Pulz, M., Kuczius, T., Ammon, A. \& Karch, H. (2002). Escherichia coli harbouring Shiga toxin 2 gene variants: frequency and association with clinical symptoms. J Infect Dis 185, 74-84.

Friedrich, A. W., Nierhoff, K. V., Bielaszewska, M., Mellmann, A. \& Karch, H. (2004). Phylogeny, clinical associations, and diagnostic utility of the pilin subunit gene $(s f p A)$ of sorbitol-fermenting, enterohemorrhagic Escherichia coli $\mathrm{O} 157: \mathrm{H}^{-}$. J Clin Microbiol 42, 4697-4701.

Friedrich, A. W., Köck, R., Bielaszewska, M., Zhang, W., Karch, H. \& Mathys, W. (2005). Distribution of the urease gene cluster among and urease activities of enterohemorrhagic Escherichia coli O157 isolates from humans. J Clin Microbiol 43, 546-550.

Friedrich, A. W., Lu, S., Bielaszewska, M., Prager, R., Bruns, P., Xu, J. G., Tschape, H. \& Karch, H. (2006). Cytolethal distending toxin in Escherichia coli O157: H7: spectrum of conservation, structure, and endothelial toxicity. J Clin Microbiol 44, 1844-1846.

Haghjoo, E. \& Galan, J. E. (2004). Salmonella typhi encodes a functional cytolethal distending toxin that is delivered into host cells by a bacterial-internalization pathway. Proc Natl Acad Sci U S A 101, 4614-4619.

Janka, A., Bielaszeweska, M., Dobrindt, U. \& Karch, H. (2002). Identification and distribution of the enterohemorrhagic Escherichia 
coli factor for adherence (efal) gene in sorbitol-fermenting Escherichia coli $\mathrm{O} 157: \mathrm{H}^{-}$. Int J Med Microbiol 292, 207-214.

Janka, A., Bielaszewska, M., Dobrindt, U., Greune, L., Schmidt, M. A. \& Karch, H. (2003). Cytolethal distending toxin gene cluster in enterohemorrhagic Escherichia coli O157: $\mathrm{H}^{-}$and O157:H7: characterization and evolutionary considerations. Infect Immun 71, 3634-3638.

Janka, A., Becker, G., Sonntag, A. K., Bielaszewska, M., Dobrindt, U. \& Karch, H. (2005). Presence and characterization of a mosaic genomic island which distinguishes sorbitol-fermenting enterohemorrhagic Escherichia coli $\mathrm{O} 157: \mathrm{H}^{-}$from E. coli O157:H7. Appl Environ Microbiol 71, 4875-4878.

Johnson, W. M. \& Lior, H. (1987). Response of Chinese hamster ovary cells to a cytolethal distending toxin (CDT) of Escherichia coli and possible misinterpretation as heat-labile (LT) enterotoxin. FEMS Microbiol Lett 43, 19-23.

Johnson, W. M. \& Lior, H. (1988a). A new heat-labile cytolethal distending toxin (CLDT) produced by Campylobacter spp. Microb Pathog 4, 115-126.

Johnson, W. M. \& Lior, H. (1988b). A new heat-labile cytolethal distending toxin (CLDT) produced by Escherichia coli isolates from clinical material. Microb Pathog 4, 103-113.

Johnson, J. R. \& Stell, A. L. (2000). Extended virulence genotypes of Escherichia coli strains from patients with urosepsis in relation to phylogeny and host compromise. J Infect Dis 181, 261-272.

Johnson, J. R., Oswald, E., O’Bryan, T. T., Kuskowski, M. A. \& Spandjaard, L. (2002). Phylogenetic distribution of virulenceassociated genes among Escherichia coli isolates associated with neonatal meningitis in the Netherlands. J Infect Dis 185, 774-784.

La Ragione, R. M. \& Woodward, M. J. (2002). Virulence factors of Escherichia coli serotypes associated with avian colisepticaemia. Res Vet Sci 73, 27-35.

Lara-Tejero, M. \& Galan, J. E. (2001). CdtA, CdtB, and CdtC form a tripartite complex that is required for cytolethal distending toxin activity. Infect Immun 69, 4358-4365.

Mainil, J. G., Jacquemin, E. \& Oswald, E. (2003). Prevalence and identity of $c d t$-related sequences in necrotoxigenic Escherichia coli. Vet Microbiol 94, 159-165.

Mayer, M. P., Bueno, L. C., Hansen, E. J. \& DiRienzo, J. M. (1999). Identification of a cytolethal distending toxin gene locus and features of a virulence-associated region in Actinobacillus actinomycetemcomitans. Infect Immun 67, 1227-1237.

Morabito, S., Dell'Omo, G., Agrimi, U., Schmidt, H., Karch, H., Cheasty, T. \& Caprioli, A. (2001). Detection and characterization of Shiga toxin-producing Escherichia coli in feral pigeons. Vet Microbiol 82, 275-283.

Nougayrede, J. P., Taieb, F., De Rycke, J. \& Oswald, E. (2005). Cyclomodulins: bacterial effectors that modulate the eukaryotic cell cycle. Trends Microbiol 13, 103-110.

Okeke, I. N., Lamikanra, A., Steinruck, H. \& Kaper, J. B. (2000). Characterization of Escherichia coli strains from cases of childhood diarrhea in provincial southwestern Nigeria. J Clin Microbiol 38, $7-12$.

Okuda, J., Kurazono, H. \& Takeda, Y. (1995). Distribution of the cytolethal distending toxin A gene $(c d t A)$ among species of Shigella and Vibrio, and cloning and sequencing of the $c d t$ gene from Shigella dysenteriae. Microb Pathog 18, 167-172.

Orth, D., Grif, K., Dierich, M. P. \& Würzner, R. (2006). Sorbitolfermenting Shiga toxin-producing Escherichia coli O157: indications for an animal reservoir. Epidemiol Infect 134, 719-723.

Peres, S. Y., Marches, O., Daigle, F., Nougayrede, J. P., Herault, F., Tasca, C., DeRycke, J. \& Oswald, E. (1997). A new cytolethal distending toxin (CDT) from Escherichia coli producing CNF2 blocks HeLa cell division in G2/M phase. Mol Microbiol 24, 1095-1107.

Pickett, C. L., Cottle, D. L., Pesci, E. C. \& Bikah, G. (1994). Cloning, sequencing, and expression of the Escherichia coli cytolethal distending toxin genes. Infect Immun 62, 1046-1051.

Pickett, C. L., Pesci, E. C., Cottle, D. L., Russell, G., Erdem, A. N. \& Zeytin, H. (1996). Prevalence of cytolethal distending toxin production in Campylobacter jejuni and relatedness of Campylobacter sp. cdtB gene. Infect Immun 64, 2070-2078.

Pickett, C. L., Lee, R. B., Eyigor, A., Elitzur, B., Fox, E. M. \& Stockbine, N. A. (2004). Patterns of variations in Escherichia coli strains that produce cytolethal distending toxin. Infect Immun $\mathbf{7 2}$, 684-690.

Prager, R., Annemüller, S. \& Tschäpe, H. (2005). Diversity of virulence patterns among Shiga toxin-producing Escherichia coli from human clinical cases - need for more detailed diagnostics. Int J Med Microbiol 295, 29-38.

Scott, D. A. \& Kaper, J. B. (1994). Cloning and sequencing of the genes encoding Escherichia coli cytolethal distending toxin. Infect Immun 62, 244-251.

Sonntag, A. K., Zenner, E., Karch, H. \& Bielaszewska, M. (2005a). Pigeons as a possible reservoir of Shiga toxin 2f-producing Escherichia coli pathogenic to humans. Berl Munch Tierarztl Wochenschr 118, 464-470.

Sonntag, A. K., Bielaszewska, M., Mellmann, A., Dierksen, N., Schierack, P., Wieler, L. H., Schmidt, M. A. \& Karch, H. (2005b). Shiga toxin 2e-producing Escherichia coli isolates from humans and pigs differ in their virulence profiles and interactions with intestinal epithelial cells. Appl Environ Microbiol 71, 8855-8863.

Starcic, M., Johnson, J. R., Stell, A. L., van der Goot, J., Hendriks, H. G., van Vorstenbosch, C., van Dijk, L. \& Gaastra, W. (2002). Haemolytic Escherichia coli isolated from dogs with diarrhea have characteristics of both uropathogenic and necrotoxigenic strains. Vet Microbiol 85, 361-377.

Toth, I., Herault, F., Beutin, L. \& Oswald, E. (2003). Production of cytolethal distending toxins by pathogenic Escherichia coli isolated from human and animal sources: establishment of the existence of a new $c d t$ variant (type IV). J Clin Microbiol 41, 4285-4291.

Young, V. B., Chien, C. C., Knox, K. A., Taylor, N. S., Schauer, D. B. \& Fox, J. G. (2000). Cytolethal distending toxin in avian and human isolates of Helicobacter pullorum. J Infect Dis 182, 620-623. 